\title{
Az Gören Bir Bireyde Ergoterapi Müdahale Programının Bireyin Günlük Yaşam Aktivitelerine Etkisinin İncelenmesi: Olgu Çalışması
}

An Investigation of the Effects of Individualized Person-Centered Occupational Therapy Intervention Program on Individual Daily Living Activities: A Case Study

Seval CEVHER ${ }^{1}$, Dilek GÜVEN ${ }^{2}$

${ }_{1}^{1}$ Ergoterapist, Şişli Hamidiye Etfal Eğitim ve Araştırma Hastanesi, Ergoterapi Ünitesi, İstanbul, Türkiye

${ }^{2}$ Prof. Dr., Şişli Hamidiye Etfal Eğitim ve Araştırma Hastanesi, Göz Kliniği, İstanbul, Türkiye

\section{öz}

\begin{abstract}
Amaç: Genetik bir hastalık olan retinis pigmentosa nedeniyle görme azlığı olan bir bireyde, ergoterapi müdahalelerinin günlük yaşam aktivitelerinin bağımsızlığına ve depresyon-anksiyete durumuna etkisini belirlemekti. Gereç ve Yöntem: Kişi merkezli olan bu çalı̧̧maya ergoterapi ünitesine başvuran 46 yaşında bir kadın retinis pigmentosa hastası dahil edildi. Model Of Human Occupation (MOHO) doğrultusunda değerlendirme ve müdahale programı oluşturuldu. 6 ay, haftada bir gün, 45 dakikalık seanslarla, ergoterapist tarafından uygulandı. Barthel Günlük Yaşam Aktiviteleri Skalası, Lawton-Brody Enstrümental Günlük Yaşam Aktiviteleri Ölçeği, Beck Depresyon ve Anksiyete Skalası ve Berg Denge Ölçeği müdahale programı uygulaması öncesi ve sonrası uygulandı. Sonuçlar: Barthel GYA puanı 80'den 100'e, Lawton-Brody EGYA 11'den 14'e yükseldi. Beck anksiyete 34'ten 29'a ve Beck depresyon puanı 26'tan 18'e düştü. Berg denge ölçeği 33 iken 39'a artış gösterdi. Tartışma: Olgumuzda el hareketleri seviyesi görmeye sahip bireyde $\mathrm{MOHO}$ temelli ergoterapi müdahalelerinin bireyin fonksiyonelliği ve bağımsızlığına, depresyon ve anksiyete durumuna olumlu etkisinin olduğu görülmüştür.
\end{abstract}

Anahtar Kelimeler: Retinis pigmentosa; Az gören; Ergoterapi

\section{ABSTRACT}

Purpose: To determine the effect of occupational therapy interventions on the independence of daily life activities and the depression-anxiety state in an individual with low vision due to retinitis pigmentosa which is a genetic disease. Materials and Method: A 46-year-old woman with retinis pigmentosa who was been admitted to the occupational therapy unit was included in this person-centered study. Evaluation and intervention program was created in line with Model of Human Occupation (MOHO). She was administered by an occupational therapist for 6 months, one day a week, with 45 -minute sessions. Barthel Daily Living Activities Scale, Lawton-Brody Instrumental Activities of Daily Living Scale, Beck Depression and Anxiety Scale and Berg Balance Scale were performed before and after the intervention program. Results: Barthel ADL score increased from 80 to 100, Lawton-Broody IADL increased from 11 to 14. Beck anxiety decreased from 34 to 29 and Beck depression score decreased from 26 to 18 . Berg balance score increased from 33 to 39. Conclusion: Occupational therapy interventions based on Model of Human Occupation (MOHO) have positive effects on functions, independence and depression-anxiety state in this individual whose eyesight is in hand motion detection level.

Keywords: Retinitis pigmentosa; Low vision; Occupational therapy 
Az görme tüm düzeltmelere rağmen, iyi görebilen gözün görme keskinliğinin 6/18'den az veya görme alanının 20 dereceden az olmasıdır. Körlük, iyi görebilen gözün görmesinin 3/60'dan az ya da görme alanının 10 derecenin altında olmasıdır (Resnikoff, Pascolini, Etya'Ale ve ark., 2004).

Katarakt, malnutrisyon, enfeksiyon, makula ve optik sinir hastalıkları, glokom, retinis pigmentosa ve yaşa bağı makula dejenerasyonu körlük nedenleri arasındadır (Bakbak, Gedik ve Güzel, 2011; Guven, Weiland ve Humayun, 2005).

Retinis pigmentosa; fotoreseptör kaybına neden olur, Dünya'da 40 milyondan fazla insanı etkiler, periferden santrale görme alanı kaybı olur ve gece körlüğü görülür (Çelik ve Karagöz, 2017; Özdikici, Baykal, Suna ve ark., 1995; Tatlipinar, Ayata, Ünal ve ark., 2007).

Görme kaybı çok yaygındır ve yaşam süresinin uzamasıyla yaygınlığının artması beklenmektedir. Görme kaybı olan bireyler fonksiyonel aktivite becerilerinde, yaşam kalitesi, serbest zaman ve sosyal aktivitelere katılımda zorluk yaşamaktadır (Berger, McAteer, Schreier ve ark., 2013).

Hareketi düzeltme, hızı kontrol etme ve engelleri farketmede görme becerisi önemlidir ve görme keskinliği bireylerin denge becerilerini ve fiziksel performansını etkiler (Arslantekin ve Akı, 2016; Huri Arslantekin, Altuntaş ve ark., 2015). Görme bozukluğu olan bireylerin fiziksel aktiviteleri azalmakta ve günlük yaşam fonksiyonlarını yerine getirmekte zorlanmaktadır (Özkan, 2013; Dayanır, Eldem, İrkeç ve ark., 1995).

Görme rehabilitasyonunun amacl; kişinin ekonomik ve sosyal bağımsızlı̆ı̆ının artırılmasıdır (Aydın ve Dürük, 2003). Az gören bireylerde var olan görme yeteneğinin kullanılması ile bağımsızlık, üretkenlik ve yaşam kalitesinin artırımasıdır (Ceyhan, 2010; Özen Tunay, İdil ve ark., 2015).

Rehabilitasyon ile duygusal çöküntü, aile reaksiyonları ve kendine bakım konularındaki sorunlar azaltılabilir (Recep, Erdoğan ve Hasıripi, 2008). Ergoterapi müdahaleleri, bireylerin sosyal yeterlik ve katıımlarında etkilidir (Akı ve Sağ, 2016).

Bu çalışma ile amacımız az gören bir bireyin günlük yaşam aktiviteleri, anksiyete ve depresyon durumu, denge becerilerini değerlendirmek ve $\mathrm{MOHO}$ temelli ergoterapi müdahalelerinin etkisini incelemektir.

\section{GEREÇ VE YÖNTEM}

46 yaşında retinis pigmentosa tanılı kadın olgu, görme azlığına bağlı, bağımsızlığını kaybetmesi nedeniyle ergoterapiye başvurmuştur. Çocukluk yıllarında okulda görme azlığı şikayeti başlamış, ancak tanı konulamamıştır. Gebelik döneminde görmesinin giderek azalması nedeniyle göz doktoruna başvurusuyla retinis pigmentosa tanısı almıştır. Evli ve iki çocuk sahibidir. Olgumuzun kızı evlidir. Oğlu ve eşiyle birlikte yaşamaktadır. Yemek yapma aktivitesinde bağımsız olamamaktan, herhangi bir serbest zaman aktivitesine görme azlığı nedeniyle sahip olamamaktan, düşmekten korktuğu için yalnız başına dışarı çıkamamaktan, evde de zaman zaman düşmelerinin olmasından şikayetçidir. Yapılan aktivite analizleriyle düşmenin nedeninin denge problemi olduğu görülmüştür.

Günlük yaşam aktivitelerindeki bağımsızlığı ölçmek için Barthel Günlük Yaşam Aktiviteleri Skalası ve Lawton-Brody Enstrümental Günlük Yaşam Aktiviteleri Skalası, ruhsal durumunu değerlendirmek için Beck Anksiyete Ölçeği ve Beck Depresyon Envanteri, dengeyi değerlendirmek için Berg Denge Ölçeği uygulandı. Bu ölçekler ergoterapi müdahalelerinin etkisini ölçmek için 6 aylık müdahale programının öncesinde ve sonrasında yapıldı. Müdahale programı; haftada bir gün, 45 dakika, Şişli Hamidiye Etfal Eğitim ve Araştırma Hastanesi Ergoterapi Ünitesi'nde, ergoterapist tarafından uygulandı.

Barthel Günlük Yaşam Aktiviteleri Ölçeği; beslenme, tekerlekli sandalyeden yatağa transfer veya yatakta oturma, kişisel bakım, tuvalet kullanımı, banyoda yıkanmak, düz yüzeyde yürümek veya yürüyemiyorsa yürüyen sandalyeyi sürmek, merdiven inmek/ çıkmak, giyinmek, idrar kontrolü, dışkı kontrolü olmak üzere 10 ana başıktan oluşur ve en yüksek bağımsızlık seviyesi toplamda 100 puan üzerinden değerlendirilen bir ölçektir (Öncel, Kalaycı, Cura ve ark., 2009). Türkçe geçerlilik ve güvenirlik çalışması yapılmıştır ve inmeli hastalarda iç tutarııık 0.93 , omurilik yaralanmasında 0.88 olarak bulunmuştur (Kucukdeveci, Yavuzer, Tennant ve ark., 2000).

Lawton-Brody Yardımcı Günlük Yaşam Aktiviteleri Ölçeği; 1969 yılında toplumda yaşamak için gerekli becerileri değerlendirmek amacıyla, Lawton ve Brody tarafından geliştirildi. Telefon kullanma, yemek hazırlama, alış-veriş yapma, günlük ev işlerini yapma, çamaşır yıkama, ulaşım aracına binebilme, ilaçları kullanabilme ve para idaresi ile ilgili bilgileri içeren 8 başlıktan oluşur ve bu başlıklar kognitif ve fiziksel beceri gerektiren işlerdir. Hem ülkemizde hem de diğer ülkelerde oldukça sıklıkla kullanılan, geçerlilik ve güvenirliği yüksek bir ölçektir (Mollaoğlu, 2011; Graf, 2008).

Bireyin sosyal hayatını ve ev dışındaki 
fonksiyonlarını değerlendirir. Yardımcı günlük yaşam aktivitelerindeki zorluk temel günlük yaşam aktivitelerinden daha yaygındır (Kovar ve Lawton, 1994). 0-3 puan aralığında puan verilmektedir. Yardımcı günlük yaşam aktivitelerinde 0-8 puan bağımlı, 9-16 puan yarı bağımlı, 17-24 puan bağımsız kabul edilir (Mollaoğlu, 2011).

Beck Depresyon Envanteri ve Beck Anksiyete Envanteri Beck ve arkadaşları tarafından geliştirilen ve Türkçe uyarlaması yapılmış bir ölçektir (Tunay ve Soygüt, 2009). Ölçeğin Croncach alfa değeri Ulusoy ve ark. tarafından 0.93 olarak hesaplanmıştır (Ulusoy, Şahin ve Erkmen, 1998). Beck depresyon envanteri her biri 0-3 arasında puanlanan 21 sorudan oluşur ve 0-13 arası depresyon yok, 14-24 arası orta derece depresyon, 25-65 arası ciddi depresyon anlamına gelmektedir (Hantal, Doğu, Büyükavcı ve ark., 2014). İki yarım test ve test-tekrar test yöntemiyle katsayıları $r=78$ ve $r=65$ olarak bulunmuştur (Durak ve Palabıyıkoğlu, 1994). Beck anksiyete ölçeği 21 maddeden oluşur, 0-3 aralığında puan verilir ve yüksek puan anksiyetenin de fazlalığı olarak yorumlanır (Canan ve Ataoğlu, 2010).

Berg denge testi fonksiyonel dengeyi değerlendiren, 14 maddeden oluşan bir denge değerlendirme ölçeğidir. 0-4 arasında puanlanır ve en yüksek 56 puandır. Yüksek puan iyi dengeyi gösterir (Huri ve ark., 2015). Güvenirlik çalışmasında Cronbach alfa değeri 0.96'dır (Şahin, Büyükavcı, Sağ ve ark., 2013).

Müdahale Programı

Olgunun müdahale programı bir ergoterapi uygulama modeli olan Model Of Human Occupation (MOHO)'ya göre yapıldı. Müdahale programı; 6 ay boyunca, haftada 1 ve 45 dakikalık seanslarla uygulanmış ve ev programı ile desteklenmiştir.

$\mathrm{MOHO}$ aktivite davranışlarını düzenler ve devam eden değişim sürecini inceleyerek vaka analizine temel oluşturur (Cubie ve Kaplan, 1982).

$\mathrm{MOHO}$ modelinin ele aldığı üç fenomen vardır. Bireylerin yapmak istedikleri ve seçtikleri bireysel farklılıklar; günlük yaşamın tekrarlayan yapısı, sosyal pozisyonlar, rutinler; iyi koordine edilmiş vücut hareketleri sonucunda ortaya çıkan performans kapasitesidir. MOHO aktivitelerin nasıl motive edildiğini, düzenlendiğini ve gerçekleştirdiğini açıklamak üzere oluşturulmuş bir ergoterapi modelidir (Kielhofner, 2002).

$\mathrm{MOHO}$ modeline göre olgumuzu incelersek: Irade: Bulmaca ve üç taş oyununa serbest zaman aktivitesi olarak ilgi duyuyor. Satranç oyununu öğrenmek istedi. Eskiden örgü ördüğünü ve bunu çok özlediğini, yeniden yapmak istediğini ifade etti.
Komşusunun havlu ve giysilere boncuk işlediğini görüp o da ilgi duyduğunu; ama göremediği için yapamadığını, denediğini ve başaramadığını anlattı. Alışkanlıklar: Anne ve eş rolü var. Evdeki tüm işlerden sorumludur. Aile bütçesine katkıda bulunmak istiyor.

Performans kapasitesi: Görme azlığı nedeniyle mutfaktaki eşyaları göremediği için yemek yapmakta zorlanıyor. Düşmekten korktuğu için mobilitede bağımsız olamamaktadır. Bulmaca ve üç taşı göremediği için yapamıyor. Satranç tahtası üzerindeki taşları göremiyor. Tırnaklarını kesebiliyor; ancak zaman zaman kesik ve kanamalar olabiliyor.

Üç taş oyunu, satranç ve bulmaca adapte edildi. Daha büyük materyal kullanıldı ve taktil uyaranlar kullanıldı. Örgü örme aktivitesi daha kalın şiş, kontrast örgü ipi ve şiş ile uyarlanarak yeniden başlaması için desteklendi. Yapmak istediği boncuk işleme aktivitesi kontrast renk seçimleri ve büyüklüğü olguya göre uyarlanarak çalışıldı. Gelir kazanma isteği doğrultusunda mesleki rehabilitasyon ile ilgili çalışmalar yapıldı; ancak çalışabileceği bir iş bulamadı ve kendini tam zamanlı bir işte çalışmaya hazır hissetmedi. Bu nedenle serbest zaman aktivitesi olarak başlanılan boncuk işleme aktivitesi gelir elde etmek için teşvik edildi. Zaten hoşlandığı bir aktivite olduğu için bu fikri kabullendi.

Ev içi düzenlemeler yapıldı ve seanslarda yemek pişirme aktivitesinin parametreleri çalışıldı. Kontrastlık ve aydınlatma ile ilgili düzenlemeler yapıldı, taktil duyusu kullanılarak malzemeleri bulmak kolaylaştırıldı.

Tırnak keserken yaralanmayı önlemek için aktivite analiz edildi ve önce daha az kısaltıp daha sonra törpüleyerek aktivite çalışıldı. Koyu renkli zemin ve masa lambası kullanıldı.

Oğlu ile görüşüldü ve aile eğitimi verildi. Aile bireylerinin daha destekleyici olması için az görme ve retinis pigmentosa hastalığı hakkında bilgi verildi. Ev düzenlemeleri için ve gelecekte yapılacak değişiklikler için aydınlatma, kontrastlık ve büyüklüğün olgunun hayatını nasıl kolaylaştıracağı ve dikkat edilmesi gerekenler, şu an evde yapılması gereken değişiklikler anlatıldı ve yapılanlar kontrol edildi.

\section{SONUÇLAR}

Olguya uygulanan Barthel GYA skalasında toplam puan 80 iken 100 oldu. Olgunun mobilite, merdiven inip çıkma, yıkanma, kendine bakım (tırnak kesme) alanlarında bağımsızlığı arttı. Lawton-Broody enstrümental günlük yaşam aktiviteleri skalası toplam puanı 11'den 14'e yükselmiştir. Olgunun 
yemek hazırlama ve yolculuk alanlarında bağımsızlığı arttı. Beck anksiyete skoru 34 iken 29 oldu. Beck depresyon skoru 26 iken 18'e düştü. Berg denge ölçeği puanı 33'ten 39'a yükseldi.

\section{TARTIŞMA}

Çalışmamızda ergoterapi müdahalelerinin retinis pigmentosa hastası ve el hareketleri seviyesi görme düzeyine sahip olgunun temel ve yardımcı günlük yaşam aktivitelerindeki bağımsızlığında artış, depresyon ve anksiyete düzeyinde azalma, denge becerisinde gelişme görülmesi ile olumlu sonuçlar elde edildi.

Serbest zaman aktiviteleri sağlık ve iyi olma hali için önem taşır. Görme problemi sosyal hayata katılımda probleme neden olur (Rees, Tee, Marella ve ark., 2010). Sosyal katılımın engellenmesi; izolasyon, yalnızlık ve depresyona yol açar. Serbest zaman ve sosyal aktiviteler depresyonun azalmasında rol oynamaktadır (Berger ve ark., 2013).

Olguya uygulanan müdahale programında seansları süresince seçilen anlamlı ve amaçlı aktiviteler ile görme öncesi ilgi duyduğu aktiviteleri geri kazanma ve yeni serbest zaman aktivitesi edindirme hedeflendi. Sosyal katılımı neredeyse yok denecek kadar az iken, ev dışında daha çok aktiviteye katılım sağlandı. Komşu ve akrabaları ile daha sık görüşmeye ve zaman geçirmeye başladı.

Çalışmamızın başında olgumuz düşme korkusu olduğunu ve mobilizasyonda kısıtılık yaşadığını ifade etti ve bunun üzerine denge testi ve denge çalışmaları yapıldı ve olumlu sonuç alındı.

İyi bir denge, vücut hareketlerinin kontrolünde önemlidir (Chen, Fu, Chan ve ark., 2012). Pozisyonun devam ettirilmesi, pozisyon değişikliklerine karşı stabilitenin sağlanması, bağımsız hareket becerileri için denge önemlidir (Huri ve ark., 2015).

Ülkemizde yeni olan ergoterapi mesleğinde az gören rehabilitasyonunda çalışan ergoterapist sayısı oldukça azdır. Herhangi bir tedavi imkanı olmayan az gören bireyler, az gören rehabilitasyon programları ile desteklenmelidir. Biz de yaptığımız çalışma ile multidisipliner çalışma ekibinde ergoterapistin az gören rehabilitasyonundaki rolü ve bireyin bağımsızlığına katkısı hakkında bilgi vermeyi hedefledik.

\section{Kaynaklar}

Akı, E. \& Sağ, R. (2016). Az gören çocuklarda birey merkezli eğitimin grup içi sosyal yeterliğe etkisinin incelenmesi. Ergoterapi ve Rehabilitasyon Dergisi, 4(1), 27-34.
Altunay Arslantekin, B., \& Akı, E. (2016). Türkiye'deki görme engelliler ve kaynaştırma okullarında öğrenim gören görme engelli öğrencilerin yürüme becerileri ve postürün değerlendirilmesi. Ergoterapi ve Rehabilitasyon Dergisi, 4(3), 181-188.

Aydın, A., \& Dürük, K. (2003). Görsel rehabilitasyon ve görsel yardım aletleri. Turkiye Klinikleri J Ophthalmol, 12(2), 116120.

Bakbak, B., Gedik, Ş., \& Güzel, H. (2011). Az görenlere yardım cihazı uygulamaları ve klinik sonuçlarımız. Ret-Vit, 19, 246-249.

Berger, S., McAteer, J., Schreier, K., \& Kaldenberg, J. (2013). Occupational therapy interventions to improve leisure and social participation for older adults with low vision: a systematic review. Am J Occup Ther, 67(3), 303-311.

Canan, F., \& Ataoğlu, A. (2010). Anksiyete, depresyon ve problem çözme becerisi algısı üzerine düzenli sporun etkisi. Anadolu Psikiyatr Derg, 11(38), 38-43.

Ceyhan, D. (2010). Makula hastalıklarında görme rehabilitasyonu. Ret-Vit, 18(4), 151-157.

Chen, E. W., Fu, A. S., Chan, K., \& Tsang, W. W. (2012). Balance control in very old adults with and without visual impairment. Eur J Appl Physiol, 112(5), 1631-1636.

Cubie, S. H., \& Kaplan, K. (1982). A case analysis method for the model of human occupation. Am J Occup Ther, 36(10), 645-656

Çelik, M. E., \& Karagöz, İ. (2017). Elektrot etkileşimi ve uyartım eşiğinin azaltılmasına yönelik sonlu elemanlar yöntemi tabanlı yeni bir retina uyartım stratejisi. Gazi Üniversitesi Mühendislik-Mimarlık Fakültesi Dergisi, 32(2), 563-573.

Dayanır, V., Eldem, B., İrkeç, M., \& Sanaç, A. Ş. (1995). Düşük görmeye yardımcı cihaz uygulamaları ve sonuçları. Turkiye Klinikleri J Ophthalmol, 4(1), 17-20.

Durak, A., \& Palabıyıkoğlu, R. (1994). Beck Umutsuzluk Ölçeği geçerlilik çalışması. Kriz Dergisi, 2(2), 311-319.

Graf, C. (2008). The Lawton Instrumental Activities of Daily Living Scale. Am J Nurs, 108(4), 52-62.

Guven, D., Weiland, J. D., \& Humayun, M. S. (2005). Retinal protezler. Ret-Vit, 13(4), 247-256.

Hantal, A. Ö., Doğu, B., Büyükavcı, R., \& Kuran, B. (2014). İnme Etki Ölçeği 3, 0: Türk toplumundaki inmeli hastalarda güvenilirlik ve geçerlilik çalışması. Türk Fiz Tıp Rehab Derg, 60, 106-116.

Huri, M., Arslantekin, B. A., Altuntaş, O., \& Akı, E. (2015). Görme keskinliği ile fonksiyonel denge arasındaki ilişkinin incelenmesi. Ergoterapi ve Rehabilitasyon Dergisi, 3(1), 7-12.

Kielhofner, G. (2002). A Model Of Human Occupation: Theory and Application, (Forth Edition). Baltimore: Lippincott Williams \& Wilkins.

Kovar, M. G., \& Lawton, M. P. (1994). Functional disability: activities and instrumental activities of daily living. Annu Rev Gerontol Geriatr, 14, 57-57.

Kucukdeveci, A. A., Yavuzer, G., Tennant, A., Suldur, N., Sonel, B., \& Arasil, T. (2000). Adaptation of the Modified Barthel İndex for use in physical medicine and rehabilitation in Turkey. Scand J Rehabil Med, 32(2): 8792.

Mollaoğlu, M. (2011). Disability, activities of daily living and self efficacy in dialysis patients. Turk Silahlı Kuvvetleri Koruyucu Hekim Bul, 10(2), 181-186.

Öncel, Ç., Kalaycı, D., Cura, Ç., Can, I., \& Kalkancı, Ö. (2009). Akut inmeli hastalarda depresyon ve kognitif bozukluk. Türk Serebrovasküler Hast Derg, 15(1), 7-11.

Özdikici, M., Baykal, O., Suna, S., Okur, A., Tüfekçi, A., \& Energin, F. (1995). Retinitis pigment franklin doppler ultrasonic bulguları. Turkiye Klinikleri J Ophthalmol, 4(2), 129-131.

Özen Tunay, Z., İdil, A., Petriçli, İ. S., \& Özdemir, Ö. (2015). Geriatrik yaş grubunda az görme rehabilitasyonu. Turk $J$ Ophthalmol, 46, 118-122.

Özkan, E. (2013). Kör ve az gören erişkin bireylerde öz yeterlilik, sosyal kaygı, başetme becerileri ve çevrenin toplumsal katılıma etkisinin incelenmesi (Yüksek Lisans Tezi). Hacettepe Üniversitesi Sağlık Bilimleri Enstitüsü, Ankara. 
Recep, Ö. F., Erdoğan, S., \& Hasıripi, H. (2008). Az gören hastalarda görsel rehabilitasyonun değerlendirilmesi. Turkiye Klinikleri J Ophthalmol, 17(2), 80-83.

Rees, G., Tee, H. W., Marella, M., Fenwick, E., Dirani, M., \& Lamoureux, E. L. (2010). Vision-specific distress and depressive symptoms in people with vision impairment. Invest Ophthalmol Vis Sci, 51(6), 2891-2896.

Resnikoff, S., Pascolini, D., Etya'Ale, D., Kocur, I., Pararajasegaram, R., Pokharel, G. P., \& Mariotti, S. P. (2004). Global data on visual impairment in the year 2002. Bull World Health Organ, 82, 844-851.

Şahin, F., Büyükavcı, R., Sağ, S., Doğu, B., \& Kuran, B. (2013). Berg Denge Ölçeği'nin Türkçe versiyonunun inmel hastalarda geçerlilik ve güvenilirliği. Türk Fiz Tıp Rehab Derg, 59(3), 170.

Tatlipinar, S., Ayata, A., Ünal, M., Aydin, A., Erşanli, D., \& Bılge, A. H. (2007). Fundus otofloresansının herediter retina hastalıklarında kullanımı. Ret-Vit, 15(2), 77-80.

Tunay, Ş., \& Soygüt, G. (2009). Türk üniversite öğrencileri üzerinde Endişe Şiddeti Ölçeği'nin güvenirlik ve geçerliği. Turk Psikiyatri Derg, 20(1), 68-74.

Ulusoy, M., Şahin, N., H., Erkmen, H. (1998). The Beck Anxiety Inventory: psychometric properties. Int $J$ Cogn Ther, 12(2), 163. 
[BU SAYFA BILEREK BOŞ BIRAKILMIŞTIR] 